\title{
Measuring the Master Adaptive Learner: Development and Internal Structure Validity Evidence for a New Instrument
}

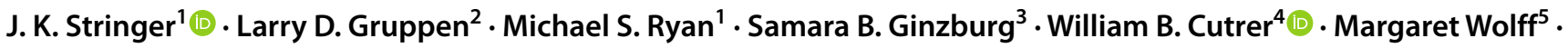 \\ Sally A. Santen ${ }^{1,6}(1)$
}

Accepted: 8 December 2021 / Published online: 4 January 2022

(c) The Author(s) under exclusive licence to International Association of Medical Science Educators 2021

\begin{abstract}
Background The master adaptive learner (MAL) uses self-regulated learning skills to develop adaptive, efficient, and accurate skills in practice. Given rapid changes in healthcare, it is essential that medical students develop into MALs. There is a need for an instrument that can capture MAL behaviors and characteristics. The objective of this study was to develop an instrument for measuring the MAL process in medical students and evaluate its psychometric properties.

Methods As part of curriculum evaluation, 818 students completed previously developed instruments with validity evidence including the Self-Regulated Learning Perception Scale, Brief Resilience Scale, Goal Orientation Scale, and Jefferson Scale of Physician Lifelong Learning. The authors performed exploratory factor analysis to examine underlying relationships between items. Items with high factor loadings were retained. Cronbach's alpha was computed. In parallel, the multiinstitutional research team rated the same items to provide content validity evidence of the items to MAL model.

Results The original 67 items were reduced to 28 items loading onto four factors: Planning, Learning, Resilience, and Motivation. Each subscale included the following number of items and Cronbach's alpha: Planning (10 items, alpha $=0.88$ ), Learning (6 items, alpha $=0.81)$, Resilience ( 6 items, alpha $=0.89)$, and Motivation $(6$ items, alpha $=0.81)$. The findings from the factor analyses aligned with the research team ratings of linkage to the components of MAL.

Conclusion These findings serve as a starting point for future work measuring master adaptive learning to identify and support learners. To fully measure the MAL construct, additional items may need to be developed.
\end{abstract}

Keywords Medical students $\cdot$ Self-regulated learning $\cdot$ Goal setting $\cdot$ Survey

Medical schools need to prepare students for work that is complex and ever evolving. In addition to developing the

Sally A. Santen

Sally.santen@vcuhealth.org

1 Virginia Commonwealth University School of Medicine, 1201 E Marshall St, MMEC 4-214, Box 980565, Richmond, VA 23298-0565, USA

2 Department of Learning Health Sciences, University of Michigan Medical School, Ann Arbor, MI, USA

3 Zucker School of Medicine at Hofstra/Northwell, Hempstead, NY, USA

4 Vanderbilt University School of Medicine, Nashville, TN, USA

5 University of Michigan Medical School, Ann Arbor, MI, USA

6 University of Cincinnati College of Medicine, Cincinnati, $\mathrm{OH}, \mathrm{USA}$ knowledge and skills required to achieve competence, physicians must refine their practice amidst rapid changes in science, technology, and public health crises $[1,2]$. The COVID-19 pandemic underscores the importance of adaptability now more than ever. Front-line providers care for increasingly complex patients and must rapidly incorporate new evidence into their daily practice and address novel challenges, thus demonstrating the application of adaptive expertise. In order to ensure adaptive physicians, medical education must start with medical students and develop and promote lifelong learners ready to engage in self-regulated learning, continuous improvement, and the ability to adapt $[3,4]$. This set of skills characterizes the master adaptive learner.

The master adaptive learner [5] (MAL) model was created to be a unifying framework to guide efforts to study and instill the skills and attributes of lifelong learning. The MAL model was developed to represent 
the daily problem-solving work of students and physicians and includes the need to regularly engage in and apply new learning, and to encompass the relationship between routine and adaptive expertise [3]. Incorporated in the MAL model are four stages of self-regulated learning (SRL) [6, 7]: planning, learning, assessment, and adjustment [8]. The MAL model extends this SRL model to describe specific behaviors within each of the four phases as well as cognitive skills and internal characteristics that support SRL [9]. Curiosity, motivation, mindset, and resilience are the internal characteristics necessary for MALs [9].

Through the medical education continuum, learners must develop and refine self-regulated learning skills. Supporting training across the medical education continuum, the Liaison Committee on Medical Education requires that self-directed learning is part of the undergraduate medical education curriculum [10]. In the MAL context, we see the behavioral elements of selfregulated learning as necessary for success with selfdirected learning. The preclinical phase is a time in which many medical schools focus on engaging students in self-directed learning, but the Accreditation Council for Graduate Medical Education mandate to develop these foundational learning skills suggests that we cannot ignore SRL after medical school [11]. While undergraduate and graduate medical education programs provide learning experiences to support this development, determining the best way to assess learners' acquisition of these skills has been proven difficult [10-12]. Contributing to this challenge are the various, overlapping frameworks applicable to lifelong learning and practicebased assessment [13].

As we are directed by our accrediting bodies to support the lifelong development of our students and physicians, it is necessary to identify elements that may help us predict learners' orientations toward this kind of learning. Given the wide range of instruments available to capture cognitive, affective, and behavioral elements of the broad SRL process [14], decisions must be made about what is most salient toward leaners' growth in this area. Social cognitive theory and reciprocal determinism [15] suggest that learners' environments, behaviors, and cognitions all impact each other. Elements that fit into this framework would include supports in the learning environment for lifelong learning [16], individual selfregulated learning behaviors [17], and personal characteristics such as resilience [18] and motivation [19]. By looking at these components not as individual factors, but instead as part of the overall tapestry of a learner's career, we may be better able to understand and support high-quality learning.
The MAL model, then, represents an appealing conceptual framework for unifying some of these varied components, yet application to medical school training is underdeveloped. While the theoretical framework of the MAL model has been described, specific measures for its key constructs do not yet exist. An important next step involves the development of an instrument that may be used to identify MAL skills present in learners. Such an instrument would allow for baseline determination of MAL skills, provide the ability to test relevant hypotheses, and may set the stage for measuring the outcome of curricular interventions designed to impact MAL development. In addition, a MAL instrument may serve to provide feedback for learning and development.

The purpose of this study was to develop a shortened instrument for measuring the MAL process in medical students and evaluate its psychometric properties. To achieve this aim, we performed an exploratory factor analysis (EFA) with a pool of existing items that had the potential to measure aspects of the MAL model.

\section{Methods}

The MAL framework incorporates several constructs, many of which have previously been measured using various tools and instruments. We elected to build the MAL instrument on this foundation. We initially searched for published instruments measuring the constructs and subcomponents associated with the MAL framework. We reviewed existing instruments focusing on whether the items and constructs aligned with the MAL model. Using a consensus process, we attempted to identify the best fit with the MAL model. Based on our collective experiences and research, we identified four instruments including the Jefferson Scale of Physician Lifelong Learning - Medical Student version [16], the Self-Regulated Learning Perception Scale [17], the Brief Resilience Scale [18], and the Goal Orientation Scale [19], with 67 total items from the potential pool of instruments to be aligned with the MAL model. For this study, the decision was made to use these instruments both for their theoretical linkages and to capitalize on existing data (see "Sample" section for more details). These selected instruments and their connection to MAL phases are listed in Table 1.

\section{A Priori Content Alignment}

After the initial identification of instruments, we asked the ten members of our multi-institutional research team, as subject matter experts (SMEs) in medical education, 
Table 1 Selected instruments with content validity reflecting MAL constructs

\begin{tabular}{|c|c|c|c|}
\hline Instrument & $\begin{array}{l}\text { Number of } \\
\text { items }\end{array}$ & Subscales & $\begin{array}{l}\text { Potential MAL } \\
\text { constructs }\end{array}$ \\
\hline $\begin{array}{l}\text { Jefferson Scale of Physician Lifelong Learning - Medical } \\
\text { Student (JeffSPLL-MS) [13] }\end{array}$ & 14 & $\begin{array}{l}\text { - Learning Beliefs and Motivation } \\
\text { - Skills in Seeking Information } \\
\text { - Attention to Learning Opportunities }\end{array}$ & $\begin{array}{l}\text { Planning } \\
\text { Learning }\end{array}$ \\
\hline Self-Regulated Learning Perception Scale (SRLPS) [14]* & 34 & $\begin{array}{l}\text { - Motivation and Action to Learning } \\
\text { - Planning and Goal Setting } \\
\text { - Strategies for Learning and Assessment }\end{array}$ & $\begin{array}{l}\text { Planning } \\
\text { Learning } \\
\text { Assessing }\end{array}$ \\
\hline Brief Resilience Scale (BRS) [15] & 6 & N/A & Resilience \\
\hline Goal Orientation Scale (GO) [16] & 13 & $\begin{array}{l}\text { - Learning Goal Orientation } \\
\text { - Prove (Performance Goal) Orientation } \\
\text { - Avoid (Performance Goal) Orientation }\end{array}$ & Motivation \\
\hline
\end{tabular}

*Instrument includes a subscale not used in the current study

educational research, the MAL model, and clinical care to review these instruments $(2 \mathrm{MD} / \mathrm{PhD}, 3 \mathrm{MD} / \mathrm{MHPE} /$ MED, $2 \mathrm{MD}, 2 \mathrm{PhD}, 1$ Master all with expertise in medical education and over 80 years in medical education). After reviewing, each SME indicated their a priori judgment to map each instrument item onto the MAL behaviors (gap identification, selects learning opportunity, searchers for resources, engages in learning, tests learning, incorporates learning, curiosity, motivation, mindset, and resilience). The SMEs rated items as zero if there was no association between the item and a behavior, one if there was weak or tangential association, or two if there was a strong association. Ratings were aggregated by summing the responses for each item from all SMEs. The SMEs discussed the similarities and differences in scoring and overall results to provide the opportunity to think deeply about these items, align them with the MAL model, and analyze the evidence for content validity.

*Instrument includes a subscale not used in the current study.

\section{Sample}

The proposed $67 \mathrm{MAL}$ items were included in existing curriculum evaluation and learning environment surveys at the Virginia Commonwealth University School of Medicine (VCU-SOM). The purpose of these surveys to provide data to the medical school about trends in cognition and behavior over the course of students' careers, and as such, they were administered at several time points for each cohort of medical students. Instrument choice was aligned with strategic priorities including self-regulated learning, but also covering topics such as professional identity and tolerance for ambiguity. Data for this study came from surveys administered to
1040 students across the medical school curricula, from matriculation to graduation during the 2018-2019 and 2019-2020 academic years. Complete responses of 818 students were used for analysis, for an overall response rate of $78 \%$. Surveys were administered for each class as follows: matriculation (C2022), 8/2018; end of M1 (C2022), 6/2019; end of M2 (C2021), 4/2019; end of M3 (C2020), 3/2019; and end of M4 (C2019), 6/2019. We intentionally surveyed students in different training years for a cross-sectional analysis because the MAL model was not intended to be specific to preclinical or clinical students.

\section{Development and Analysis of MAL Instrument}

To assess validity evidence related to the internal structure of the instrument, we conducted an EFA using IBM SPSS 26 to identify potential factor structures that could summarize the data and form a basis for subscales within a new instrument and compared these findings with expert review. We followed an iterative process that involved reflecting on the quantitative findings from the EFA alongside the content of the items and our shared theoretical understandings of MAL.

\section{EFA}

Exploratory factor analysis is a statistical method that allows for latent elements in a dataset to emerge by comparing the contribution of common and unique variance. An initial factor structure was produced using principal axis factoring, extracting all factors with an eigenvalue greater than one. However, this produced a 15-factor model which was uninterpretable. Using a scree plot, the elbow was identified at three, four, and five factors, so we evaluated factor solutions ranging from each 
by forcing the extraction of those factors, respectively. The four-factor model was chosen. Follow-up analyses were conducted using a promax rotation to allow factors within the model to correlate with each other. Allowing correlations was permitted due to the interplay between MAL facets. To reduce data to create a model, items with loadings less than 0.6 were suppressed. The findings were confirmed by alignment with the SME scoring. The internal consistency of each of these factors was assessed with Cronbach's alpha. This study was reviewed and approved by the VCU Institutional Review Board and classified as exempt.

\section{Results}

Response rates from our students were as follows: 178 students at matriculation (Class of 2023, 96\%), 132 at the completion of the first year (Class of 2022, 65\%), 199 preclerkship (Class of 2021, 91\%), 156 post-clerkship (Class of 2020,70\%), and 153 prior to graduation (Class of 2019, $73 \%)$.

Individual items were allocated to the factors extracted in EFA based on their pattern matrix loadings. The four-factor model retaining 65 items with factor loadings above 0.6 was selected as the best fit based on a lack of cross loadings and conceptually distinct factors. Total variance explained by the model was $39.08 \%$ (factor $1: 22.37 \%$, factor $2: 7.12 \%$, factor $3: 5.16 \%$, factor 4: $4.43 \%$ ). These factors resulted in factor 1 having 15 items, factor 2 having six, factor 3 having six, and factor 4 having six.

To limit the number of items on the overall scale, the ten most highly loading items were retained for factor 1. All told, this process reduced the total item load from 67 to 28 with Cronbach's alpha values ranging from 0.81 to 0.89 . These factors were discussed and labeled Planning, Learning, Resilience, and Motivation (Tables 2 and 3). This labeling was achieved by comparing the items maintained in each factor with the relative weights assigned by the SMEs. For example, items remaining in the Planning factor were highly rated by SMEs as having strong associations to the planning element of the original MAL model. Appendix Table 4 presents all items and their factor loadings to detail the structure of the items that were included and excluded from the final model.

\section{Discussion}

The MAL framework was developed by Cutrer and colleagues [5] based on existing frameworks, such as selfregulated learning and motivation theory, to be a more comprehensive framework to study and promote complex learning for future competence. It describes a metacognitive approach to learning based on self-regulation that can foster the development and use of adaptive expertise. These results represent our first step in developing a shortened instrument to measure the MAL model in medical students. This preliminary instrument successfully assesses several components of MAL in a reduced fashion. Specifically, the EFA model identified four categories related to MAL including Planning, Learning, Resilience, and Motivation. Items came from the Jefferson Scale of Physician Lifelong Learning - Medical Student version [16], the Self-Regulated Learning Perception Scale [17], the Brief Resilience Scale [18], and the Goal Orientation Scale [19]. The resultant instrument is 28 items (a 58\% reduction in item load) with four subscales and reasonable internal consistency. In this work, we intentionally included students across the continuum of undergraduate medical education. While the context for each cohort of students is different from pre-clerkship, clerkship, and post-clerkship, the instrument demonstrated a shared structure across these phases of the curriculum.

The EFA identified four categories of the MAL model. The Planning phase incorporates three stages (identifying a gap, selecting an opportunity for learning, and searching for resources for learning). Items in this factor explore gap identification, goal setting, and
Table 2 Final factor structure including sample items

\begin{tabular}{llll}
\hline & & & $\begin{array}{l}\text { Cronbach's } \\
\text { alpha }\end{array}$ \\
\hline Factor 1 & Planning: 10 items & "I make a plan to utilize learning resources efficiently." & 0.88 \\
Factor 2 & Learning: 6 items & "I search for possibilities to learn new things." & 0.81 \\
Factor 3 & Resilience: 6 items & "It is hard for me to snap back when something bad hap- & 0.89 \\
& pens." & \multirow{2}{*}{0.81} \\
Factor 4 & Motivation: 6 items & "I'm concerned about taking on a task at work if my \\
& & performance would reveal that I have low ability." & \\
\hline
\end{tabular}


Table 3 Factor analysis results with four factors and factor loadings

\begin{tabular}{|c|c|c|c|c|c|c|c|}
\hline & & Original scale & 1 & 2 & 3 & 4 & Final factor inclusion \\
\hline 1 & I make a plan to utilize learning resources efficiently & SRLPS & 0.702 & -0.132 & -0.006 & -0.005 & Planning \\
\hline 2 & $\begin{array}{l}\text { I make a plan as to how I will carry out the learning } \\
\text { process }\end{array}$ & SRLPS & 0.701 & -0.118 & -0.036 & 0.045 & Planning \\
\hline 3 & $\begin{array}{l}\text { I choose the most appropriate learning approach to } \\
\text { reach my goal }\end{array}$ & SRLPS & 0.692 & -0.081 & 0.018 & -0.002 & Planning \\
\hline 4 & $\begin{array}{l}\text { I evaluate my learning approaches to see if they really } \\
\text { help me learn }\end{array}$ & SRLPS & 0.689 & 0.007 & -0.11 & -0.041 & Planning \\
\hline 5 & I prioritize my goals & SRLPS & 0.68 & -0.121 & 0.092 & 0.018 & Planning \\
\hline 6 & I assess whether or not my goals are accomplished & SRLPS & 0.669 & -0.025 & -0.018 & 0.02 & Planning \\
\hline 7 & $\begin{array}{l}\text { I evaluate my mistakes during the learning process and } \\
\text { learn from them }\end{array}$ & SRLPS & 0.667 & -0.011 & -0.01 & -0.009 & Planning \\
\hline 8 & $\begin{array}{l}\text { I identify the resources needed during the learning } \\
\text { process }\end{array}$ & SRLPS & 0.665 & -0.044 & 0.029 & 0.079 & Planning \\
\hline 9 & $\begin{array}{l}\text { I search for new strategies if those used in implement- } \\
\text { ing my plan are inadequate }\end{array}$ & SRLPS & 0.622 & 0.047 & -0.076 & -0.07 & Planning \\
\hline 10 & $\begin{array}{l}\text { I make a plan to utilize resources and strategies in } \\
\text { order to reach my goal }\end{array}$ & SRLPS & 0.619 & 0.04 & -0.015 & 0.082 & Planning \\
\hline 11 & I search for possibilities to learn new things & SRLPS & 0.028 & 0.672 & -0.057 & 0.079 & Learning \\
\hline 12 & $\begin{array}{l}\text { I enjoy challenging and difficult tasks at work where } \\
\text { I'll learn new skills }\end{array}$ & Goal Orientation & -0.008 & 0.643 & 0.079 & -0.07 & Learning \\
\hline 13 & $\begin{array}{l}\text { I often look for opportunities to develop new skills and } \\
\text { knowledge }\end{array}$ & Goal Orientation & 0.123 & 0.634 & 0.004 & -0.051 & Learning \\
\hline 14 & $\begin{array}{l}\text { I am curious about the causes of things I see, hear, or } \\
\text { read }\end{array}$ & SRLPS & -0.037 & 0.633 & 0.019 & 0.069 & Learning \\
\hline 15 & $\begin{array}{l}\text { I recognize my need to constantly acquire new profes- } \\
\text { sional knowledge }\end{array}$ & Lifelong Learning & -0.068 & 0.608 & -0.062 & -0.004 & Learning \\
\hline 16 & I take every opportunity to learn new things & SRLPS & 0.102 & 0.607 & -0.07 & 0.029 & Learning \\
\hline 17 & $\begin{array}{l}\text { It is hard for me to snap back when something bad } \\
\text { happens }\end{array}$ & Brief Resilience & -0.002 & -0.105 & 0.843 & -0.017 & Resilience \\
\hline 18 & I tend to take a long time to get over setbacks in my life & Brief Resilience & 0.041 & -0.079 & 0.807 & -0.014 & Resilience \\
\hline 19 & I have a hard time making it through stressful events & Brief Resilience & -0.029 & -0.039 & 0.778 & 0.025 & Resilience \\
\hline 20 & I tend to bounce back quickly after hard times & Brief Resilience & -0.01 & 0.013 & 0.755 & 0.034 & Resilience \\
\hline 21 & $\begin{array}{l}\text { It does not take me long to recover from a stressful } \\
\text { event }\end{array}$ & Brief Resilience & -0.05 & -0.04 & 0.755 & 0.033 & Resilience \\
\hline 22 & I usually come through difficult times with little trouble & Brief Resilience & -0.016 & -0.02 & 0.681 & 0.06 & Resilience \\
\hline 23 & $\begin{array}{l}\text { I'm concerned about taking on a task at work if my } \\
\text { performance would reveal that I have low ability }\end{array}$ & Goal Orientation & 0.011 & -0.121 & -0.104 & 0.697 & Motivation \\
\hline 24 & $\begin{array}{l}\text { I prefer to work on projects where I can prove my abil- } \\
\text { ity to others }\end{array}$ & Goal Orientation & -0.042 & 0.258 & 0.132 & 0.69 & Motivation \\
\hline 25 & $\begin{array}{l}\text { I enjoy it when others at work are aware of how well I } \\
\text { am doing }\end{array}$ & Goal Orientation & -0.028 & 0.222 & 0.124 & 0.676 & Motivation \\
\hline 26 & $\begin{array}{l}\text { I prefer to avoid situations at work where I might } \\
\text { perform poorly }\end{array}$ & Goal Orientation & 0.029 & -0.204 & -0.113 & 0.663 & Motivation \\
\hline 27 & $\begin{array}{l}\text { I try to figure out what it takes to prove my ability to } \\
\text { others at work }\end{array}$ & Goal Orientation & 0.037 & 0.205 & 0.087 & 0.635 & Motivation \\
\hline 28 & $\begin{array}{l}\text { I would avoid taking a new task if there was a chance } \\
\text { that I would appear rather incompetent to others }\end{array}$ & Goal Orientation & 0.05 & -0.161 & -0.093 & 0.623 & Motivation \\
\hline 29 & $\begin{array}{l}\text { Avoiding a show of low ability is more important to me } \\
\text { than learning a new skill }\end{array}$ & Goal Orientation & 0.004 & -0.238 & -0.073 & 0.586 & Not included \\
\hline 30 & $\begin{array}{l}\text { I'm concerned with showing that I can perform better } \\
\text { than my coworkers }\end{array}$ & Goal Orientation & -0.008 & 0.183 & 0.024 & 0.535 & Not included \\
\hline
\end{tabular}

SRLPS Self-Regulated Learning Perception Scale 
resource identification. The items in this factor were from the Self-Regulated Learning Perception Scale (SRLPS). In the Learning phase, the student begins to engage in the learning process through challenges and opportunities, and items in this factor were from Goal Orientation and SRLPS. In addition to the process of MAL, there are "batteries" or internal characteristics that facilitate the MAL process. Of these, the EFA identified items associated with Motivation and Resilience. Not surprisingly, the Brief Resilience Scale factored to Resilience. Similarly, Goal Orientation items represented Motivation.

The EFA did not identify factors associated with Assessing and Adjusting. Similarly, the a priori content alignment content alignment by the subject matter expert panel did not map these domains. It is interesting to note that despite the fact that the Jefferson Scale of Physician Lifelong Learning [16] and SRLPS [17] are commonly used to assess learning, neither instrument robustly represented assessment or adjustment, which are very important parts of any self-regulated or lifelong learning process. Next, future work will include questions that delve into the specific aspects of Assessing and Adjusting. If we find that existing tools do not contain these questions, one explanation could be that our understanding of self-regulated learning through the development of the MAL model has matured to recognize these specific pieces as important, and if that is the case, we will work with SMEs to create the needed questions. As we explored motivation through the SME, the items, and the MAL model, it is likely that curiosity, motivation, and mindset are interconnected, and it may not be possible to separate into subscales. The researchers on this team believe the theory of MAL is reasonably sound, and we are interested in exploring this further through a wider search for questions from new instruments, specifically focused on these areas, for inclusion in a future EFA study. We hypothesize that by grounding future item development in the lived experiences of learners, a novel instrument can be developed that will account for a greater degree of variance in scores than this first draft shortened version.

\section{Potential Implications}

There are several important implications to these results. First, an instrument that measures the MAL construct may provide valuable diagnostic information. If a learner struggles with clinical reasoning or has context-specific challenges, a MAL instrument may help identify the domain of these issues and may streamline efforts for remediation. Second, via further exploration of master adaptive learning through the lens of this instrument, we hope to better understand the development of students' learning processes. The ability to assess learners utilizing a MAL framework will be a tangible way to codify areas for individual growth and facilitate research into the best ways to fill those gaps. The COVID-19 pandemic has exemplified how adaptive our practitioners can be when faced with the unknown.

Finally, these results may offer opportunity for answering existing or future research questions related to the framework. For example, is master adaptive learning a fixed or variable characteristic? Do some learners approach situations in a method more in-line with this framework? If so, what are the short- and long-term outcomes? Are there multiple ways to accomplish each part of the framework and what are they? The MAL instrument may help explore these questions while acknowledging the limitations of utilizing a self-reported instrument. Finally, a MAL instrument may provide feedback to students about their approach to adaptive learning.

\section{Next Steps}

The current instrument covers four aspects of master adaptive learning, but additional domains are needed. We will gather additional instruments and/or develop novel items to capture a more comprehensive picture of master adaptive learning. In addition, we will explore the administration of the instrument at other institutions along with additional factor analysis. Finally, it may be useful to analyze separately cohorts of preclinical and clinical students.

Through this work, we also recognize that master adaptive learning is complex in nature, and to adequately assess it, we will need to include behavioral measures which may not lend themselves to a traditional self-report format. How can the information gathered through student self-report be combined with workplace-based assessment? How do narrative assessments from faculty coaches align with students' perceptions? Furthermore, there is much value in testing this framework on learners in other contexts.

The overall MAL process is important as well as the relationships to all the steps and the batteries. It may be important to consider instrument development in terms of a programmatic assessment of this complex, 
multifaceted construct $[20,21]$. The development of an overall assessment instrument to measure master adaptive learning and the subscales may contribute to a portfolio effort to measure components of MAL and assemble those assessments into an overall assessment of the master adaptive learner.

\section{Limitations}

EFA has an inherent limitation in that data analysis can only show results based on the existing items and respondents and an assumption is made that the resulting factor structure is a best fit of those data. Furthermore, the addition of novel items or modifications of item wording may change the internal structure of the aggregate instrument and alter this solution. There are also a wide range of other surveys that could be used to capture the constructs of interest in slight or significantly different ways. In terms of selected instruments, the SRLPS has four subscales, and we included three of the subscales (the "lack of self-directedness" subscale was excluded). Interestingly, the 3 we used did not load together into those three subscales which may be illustrative of the fact that context is important. It is also worth to consider the four areas of the MAL model that are not part of this preliminary tool (Assessing, Adjusting, Curiosity, Mindset) and considering why this may have happened. There are several possibilities:

- We did not have the right collection of instruments in this study.

- The questions from the instruments we used may not be sensitive enough to discriminate the various categories of the MAL model.

- The phases of the MAL model are not as distinct as described, and there is some overlap among them which would suggest the MAL construct needs some adjustment.
- The MAL model needs further development to align with authentic learning.

We will need to collect additional validity evidence on a new sample of student responses to judge the stability and generalizability of the four-factor solution. We made the decision to group the cohort data together based on academic phase because there were no significant curricular changes, but other factors could result in bias by merging this data. It is also important that future studies include the perspectives of students in special populations and use instrumentation that has been validated for those populations such as the Metacognitive Awareness Inventory [22]. We are also limited by the instruments that we selected to begin with. This is a single institution study which limits generalizability. While the goal was to create an instrument that applies across all years of medical school, it may be that the items do not adequately reflect learner skills and development during every phase.

\section{Conclusions}

Master adaptive learning is multidimensional, and the current instrument identifies four important domains. The MAL model provides a practical framework to guide learning across the continuum in medicine. By measuring individual components within the framework, we can support the development of these internal characteristics and behaviors throughout a learner's career. Supporting physicians at all stages of their career, whether during times of crisis or within the context of daily learning and practice, with individualized recommendations/ coaching in what areas they should focus on and with specific suggestions for how they can improve, is our professional responsibility as medical educators. A tool to assess master adaptive learners will be a key to accomplishing this. 


\section{Appendix}

Table 4 Full factor analysis results with four factors and factor loadings

\begin{tabular}{|c|c|c|c|c|c|c|c|}
\hline & & Original scale & 1 & 2 & 3 & 4 & Final factor inclusion \\
\hline 1 & I make a plan to utilize learning resources efficiently & SRLPS & 0.702 & -0.132 & -0.006 & -0.005 & Planning \\
\hline 2 & $\begin{array}{l}\text { I make a plan as to how I will carry out the learning } \\
\text { process }\end{array}$ & SRLPS & 0.701 & -0.118 & -0.036 & 0.045 & Planning \\
\hline 3 & $\begin{array}{l}\text { I choose the most appropriate learning approach to } \\
\text { reach my goal }\end{array}$ & SRLPS & 0.692 & -0.081 & 0.018 & -0.002 & Planning \\
\hline 4 & $\begin{array}{l}\text { I evaluate my learning approaches to see if they really } \\
\text { help me learn }\end{array}$ & SRLPS & 0.689 & 0.007 & -0.11 & -0.041 & Planning \\
\hline 5 & I prioritize my goals & SRLPS & 0.68 & -0.121 & 0.092 & 0.018 & Planning \\
\hline 6 & I assess whether or not my goals are accomplished & SRLPS & 0.669 & -0.025 & -0.018 & 0.02 & Planning \\
\hline 7 & $\begin{array}{l}\text { I evaluate my mistakes during the learning process and } \\
\text { learn from them }\end{array}$ & SRLPS & 0.667 & -0.011 & -0.01 & -0.009 & Planning \\
\hline 8 & $\begin{array}{l}\text { I identify the resources needed during the learning } \\
\text { process }\end{array}$ & SRLPS & 0.665 & -0.044 & 0.029 & 0.079 & Planning \\
\hline 9 & $\begin{array}{l}\text { I search for new strategies if those used in implement- } \\
\text { ing my plan are inadequate }\end{array}$ & SRLPS & 0.622 & 0.047 & -0.076 & -0.07 & Planning \\
\hline 10 & $\begin{array}{l}\text { I make a plan to utilize resources and strategies in } \\
\text { order to reach my goal }\end{array}$ & SRLPS & 0.619 & 0.04 & -0.015 & 0.082 & Planning \\
\hline 11 & $\begin{array}{l}\text { I manage my time in order to learn as efficiently as } \\
\text { possible }\end{array}$ & SRLPS & 0.618 & -0.14 & 0.142 & 0.048 & Not included \\
\hline 12 & $\begin{array}{l}\text { After any learning assignment, I assess whether I } \\
\text { learned the material completely }\end{array}$ & SRLPS & 0.613 & -0.038 & -0.027 & -0.005 & Not included \\
\hline 13 & $\begin{array}{l}\text { I identify the learning materials that will help me to } \\
\text { learn }\end{array}$ & SRLPS & 0.608 & -0.002 & 0.045 & 0.046 & Not included \\
\hline 14 & $\begin{array}{l}\text { I strive to eliminate any difficulties I face during the } \\
\text { learning process }\end{array}$ & SRLPS & 0.607 & -0.045 & 0.025 & 0.06 & Not included \\
\hline 15 & $\begin{array}{l}\text { I clearly identify the objectives to be achieved at the } \\
\text { end of the learning process }\end{array}$ & SRLPS & 0.606 & 0.004 & 0.02 & 0.019 & Not included \\
\hline 16 & $\begin{array}{l}\text { After accomplishing my objective(s), I identify new } \\
\text { goals to achieve }\end{array}$ & SRLPS & 0.583 & 0.113 & -0.055 & -0.048 & Not included \\
\hline 17 & I strive to improve my weaknesses in learning & SRLPS & 0.576 & 0.124 & -0.023 & -0.029 & Not included \\
\hline 18 & $\begin{array}{l}\text { I use different learning strategies for the knowledge I } \\
\text { acquire to be meaningful }\end{array}$ & SRLPS & 0.557 & 0.05 & -0.053 & -0.069 & Not included \\
\hline 19 & $\begin{array}{l}\text { I objectively judge my work during the learning } \\
\text { process }\end{array}$ & SRLPS & 0.547 & -0.032 & 0.067 & -0.03 & Not included \\
\hline 20 & I continuously improve my problem-solving methods & SRLPS & 0.543 & 0.104 & 0.105 & -0.022 & Not included \\
\hline 21 & I search for ways to facilitate learning in new situations & SRLPS & 0.51 & 0.154 & -0.034 & -0.003 & Not included \\
\hline 22 & $\begin{array}{l}\text { I use different learning strategies for the acquired } \\
\text { knowledge to be sustainable }\end{array}$ & SRLPS & 0.491 & 0.083 & -0.039 & -0.03 & Not included \\
\hline 23 & $\begin{array}{l}\text { I experiment with new learning strategies until I learn } \\
\text { the material completely }\end{array}$ & SRLPS & 0.464 & 0.055 & -0.043 & -0.052 & Not included \\
\hline 24 & $\begin{array}{l}\text { I apply my newly acquired knowledge into new prob- } \\
\text { lem states }\end{array}$ & SRLPS & 0.431 & 0.156 & 0.042 & -0.017 & Not included \\
\hline 25 & I use my own strategies of learning & SRLPS & 0.389 & 0.05 & 0.069 & 0.017 & Not included \\
\hline 26 & I explore other peoples' methods of problem solving & SRLPS & 0.346 & 0.042 & -0.089 & -0.061 & Not included \\
\hline 27 & $\begin{array}{l}\text { I compare other peoples' problem solving strategies } \\
\text { with my own }\end{array}$ & SRLPS & 0.278 & 0.059 & -0.092 & 0.026 & Not included \\
\hline 28 & I search for possibilities to learn new things & SRLPS & 0.028 & 0.672 & -0.057 & 0.079 & Learning \\
\hline 29 & $\begin{array}{l}\text { I enjoy challenging and difficult tasks at work where } \\
\text { I'll learn new skills }\end{array}$ & Goal Orientation & -0.008 & 0.643 & 0.079 & -0.07 & Learning \\
\hline
\end{tabular}


Table 4 (continued)

\begin{tabular}{|c|c|c|c|c|c|c|c|}
\hline & & Original scale & 1 & 2 & 3 & 4 & Final factor inclusion \\
\hline 30 & $\begin{array}{l}\text { I often look for opportunities to develop new skills and } \\
\text { knowledge }\end{array}$ & Goal Orientation & 0.123 & 0.634 & 0.004 & -0.051 & Learning \\
\hline 31 & $\begin{array}{l}\text { I am curious about the causes of things I see, hear, or } \\
\text { read }\end{array}$ & SRLPS & -0.037 & 0.633 & 0.019 & 0.069 & Learning \\
\hline 32 & $\begin{array}{l}\text { I recognize my need to constantly acquire new profes- } \\
\text { sional knowledge }\end{array}$ & Lifelong Learning & -0.068 & 0.608 & -0.062 & -0.004 & Learning \\
\hline 33 & I take every opportunity to learn new things & SRLPS & 0.102 & 0.607 & -0.07 & 0.029 & Learning \\
\hline 34 & $\begin{array}{l}\text { I enjoy reading articles in which issues of medicine are } \\
\text { discussed }\end{array}$ & Lifelong Learning & -0.051 & 0.579 & -0.07 & 0.035 & Not included \\
\hline 35 & $\begin{array}{l}\text { I am willing to select a challenging work assignment } \\
\text { that I can learn a lot from }\end{array}$ & Goal Orientation & 0.063 & 0.559 & 0.079 & -0.089 & Not included \\
\hline 36 & $\begin{array}{l}\text { I take every opportunity to gain new knowledge/skills } \\
\text { that are important to my profession }\end{array}$ & Lifelong Learning & 0.05 & 0.558 & -0.064 & 0.019 & Not included \\
\hline 37 & $\begin{array}{l}\text { I believe that I would fall behind if I stopped learning } \\
\text { about new developments in medicine }\end{array}$ & Lifelong Learning & -0.079 & 0.557 & -0.093 & 0.115 & Not included \\
\hline 38 & $\begin{array}{l}\text { I derive new learning assignments for myself from the } \\
\text { things I observe around me }\end{array}$ & SRLPS & 0.056 & 0.536 & -0.081 & 0.037 & Not included \\
\hline 39 & $\begin{array}{l}\text { I routinely search computer databases to find out about } \\
\text { new developments in science or medicine }\end{array}$ & Lifelong Learning & -0.081 & 0.531 & -0.028 & 0.073 & Not included \\
\hline 40 & $\begin{array}{l}\text { Rapid changes in medical science require constant } \\
\text { updating of knowledge and development of new } \\
\text { professional skills }\end{array}$ & Lifelong Learning & -0.031 & 0.503 & -0.051 & 0.039 & Not included \\
\hline 41 & $\begin{array}{l}\text { For me, development of my work ability is important } \\
\text { enough to take risks }\end{array}$ & Goal Orientation & 0.021 & 0.502 & 0.151 & -0.024 & Not included \\
\hline 42 & $\begin{array}{l}\text { Searching for the answer to a question is, in and by } \\
\text { itself rewarding }\end{array}$ & Lifelong Learning & -0.089 & 0.498 & -0.034 & 0.012 & Not included \\
\hline 43 & $\begin{array}{l}\text { I prefer to work in situations that require a high level of } \\
\text { ability and talent }\end{array}$ & Goal Orientation & 0.058 & 0.482 & 0.148 & 0.024 & Not included \\
\hline 44 & I take action to learn according to my interests & SRLPS & 0.097 & 0.467 & 0.028 & 0.033 & Not included \\
\hline 45 & $\begin{array}{l}\text { I read medical literature in journals, websites or text- } \\
\text { books at least once every week }\end{array}$ & Lifelong Learning & -0.111 & 0.467 & 0.031 & 0.044 & Not included \\
\hline 46 & $\begin{array}{l}\text { I always make time for learning on my own, even when } \\
\text { I have a busy class schedule and other obligations }\end{array}$ & Lifelong Learning & 0.121 & 0.427 & -0.035 & -0.032 & Not included \\
\hline 47 & $\begin{array}{l}\text { I routinely attend optional sessions such as study } \\
\text { groups, guest lectures, or exposure to healthcare } \\
\text { experience where I can volunteer to improve my } \\
\text { knowledge and experience }\end{array}$ & Lifelong Learning & 0.061 & 0.408 & -0.125 & -0.049 & Not included \\
\hline 48 & $\begin{array}{l}\text { One of the important goals of medical school is to } \\
\text { develop students' lifelong learning skills }\end{array}$ & Lifelong Learning & 0.031 & 0.397 & -0.056 & 0.046 & Not included \\
\hline 49 & I attentively observe/examine things around me & SRLPS & 0.069 & 0.393 & 0.088 & 0.095 & Not included \\
\hline 50 & $\begin{array}{l}\text { Lifelong learning is a professional responsibility of all } \\
\text { physicians }\end{array}$ & Lifelong Learning & -0.057 & 0.382 & 0.017 & 0.016 & Not included \\
\hline 51 & $\begin{array}{l}\text { My preferred approach in finding an answer to a ques- } \\
\text { tion is to search the appropriate computer databases }\end{array}$ & Lifelong Learning & 0.036 & 0.361 & 0.013 & 0.13 & Not included \\
\hline 52 & When faced with a problem, I take action to solve it & SRLPS & 0.246 & 0.321 & 0.099 & -0.009 & Not included \\
\hline 53 & I routinely attend meetings of student study groups & Lifelong Learning & 0.166 & 0.169 & -0.051 & -0.004 & Not included \\
\hline 54 & $\begin{array}{l}\text { It is hard for me to snap back when something bad } \\
\text { happens }\end{array}$ & Brief Resilience & -0.002 & -0.105 & 0.843 & -0.017 & Resilience \\
\hline 55 & I tend to take a long time to get over setbacks in my life & Brief Resilience & 0.041 & -0.079 & 0.807 & -0.014 & Resilience \\
\hline 56 & I have a hard time making it through stressful events & Brief Resilience & -0.029 & -0.039 & 0.778 & 0.025 & Resilience \\
\hline 57 & I tend to bounce back quickly after hard times & Brief Resilience & -0.01 & 0.013 & 0.755 & 0.034 & Resilience \\
\hline 58 & $\begin{array}{l}\text { It does not take me long to recover from a stressful } \\
\text { event }\end{array}$ & Brief Resilience & -0.05 & -0.04 & 0.755 & 0.033 & Resilience \\
\hline 59 & I usually come through difficult times with little trouble & Brief Resilience & -0.016 & -0.02 & 0.681 & 0.06 & Resilience \\
\hline
\end{tabular}


Table 4 (continued)

\begin{tabular}{|c|c|c|c|c|c|c|c|}
\hline & & Original scale & 1 & 2 & 3 & 4 & Final factor inclusion \\
\hline 60 & $\begin{array}{l}\text { I'm concerned about taking on a task at work if my } \\
\text { performance would reveal that I have low ability }\end{array}$ & Goal Orientation & 0.011 & -0.121 & -0.104 & 0.697 & Motivation \\
\hline 61 & $\begin{array}{l}\text { I prefer to work on projects where I can prove my abil- } \\
\text { ity to others }\end{array}$ & Goal Orientation & -0.042 & 0.258 & 0.132 & 0.69 & Motivation \\
\hline 62 & $\begin{array}{l}\text { I enjoy it when others at work are aware of how well I } \\
\text { am doing }\end{array}$ & Goal Orientation & -0.028 & 0.222 & 0.124 & 0.676 & Motivation \\
\hline 63 & $\begin{array}{l}\text { I prefer to avoid situations at work where I might } \\
\text { perform poorly }\end{array}$ & Goal Orientation & 0.029 & -0.204 & -0.113 & 0.663 & Motivation \\
\hline 64 & $\begin{array}{l}\text { I try to figure out what it takes to prove my ability to } \\
\text { others at work }\end{array}$ & Goal Orientation & 0.037 & 0.205 & 0.087 & 0.635 & Motivation \\
\hline 65 & $\begin{array}{l}\text { I would avoid taking a new task if there was a chance } \\
\text { that I would appear rather incompetent to others }\end{array}$ & Goal Orientation & 0.05 & -0.161 & -0.093 & 0.623 & Motivation \\
\hline 66 & $\begin{array}{l}\text { Avoiding a show of low ability is more important to me } \\
\text { than learning a new skill }\end{array}$ & Goal Orientation & 0.004 & -0.238 & -0.073 & 0.586 & Not included \\
\hline 67 & $\begin{array}{l}\text { I'm concerned with showing that I can perform better } \\
\text { than my coworkers }\end{array}$ & Goal Orientation & -0.008 & 0.183 & 0.024 & 0.535 & Not included \\
\hline
\end{tabular}

Acknowledgements We would like to acknowledge Seetha Monrad, Martin Pusic, Meagan Rawls, and Kendra Parekh for their contributions as part of the research team; J. K. Stringer's dissertation committee; and Courtney Blondino, Moshe Feldman, Heather Brickley, and Kelly Lockeman.

Author contributions J. K. Stringer was a postdoctoral fellow, Office of Assessment, Evaluation, and Scholarship, Virginia Commonwealth University School of Medicine, Richmond, VA, USA, at the time of this writing and is currently an assessment manager, Rush Medical College, Chicago, IL, USA.L. D. Gruppen is a professor in the Department of Learning Health Sciences, University of Michigan Medical School, Ann Arbor, MI, USA.M. S. Ryan is the assistant dean for clinical medical education and an associate professor of pediatrics, Virginia Commonwealth University School of Medicine, Richmond, VA, USA.S. B. Ginzburg is the senior associate dean for education and an associate professor of medicine and science education, Zucker School of Medicine at Hofstra/Northwell, Hempstead, NY, USA.W. B. Cutrer is an associate professor of pediatrics and the associate dean for undergraduate medical education at the Vanderbilt University School of Medicine, Nashville, TN, USA.M. Wolff is an associate professor of emergency medicine and pediatrics, University of Michigan Medical School, Ann Arbor, MI, USA.S. A. Santen is the senior associate dean for assessment, evaluation, and scholarship, and a professor of emergency medicine, Virginia Commonwealth University School of Medicine, Richmond, VA, USA, and is a professor of emergency medicine, University of Cincinnati College of Medicine, Cincinnati, OH, USA.

Funding This work was supported by an AMA Accelerating Change Innovation Grant. VCU, University of Michigan, and Vanderbilt School of Medicine receive funding from AMA Accelerating Change in Medical Education. AMA Accelerating Change Innovation Grant

\section{Declarations}

Ethics Approval and Consent to Participate This study was reviewed and approved by the VCU Institutional Review Board and classified as exempt. Informed consent is not applicable.

Conflict of Interest The authors declare no competing interests.

\section{References}

1. Bowen JL, Ilgen JS, Regehr G, Cate OT, Irby DM, O'Brien BC. Reflections from the rearview mirror: internal medicine physicians' reactions to clinical feedback after transitions of responsibility. Acad Med J Assoc Am Med Coll. 2019;94:1953-60.

2. Richardson S, Hirsch JS, Narasimhan M, Crawford JM, McGinn $\mathrm{T}$, Davidson KW, et al. Presenting characteristics, comorbidities, and outcomes among 5700 patients hospitalized with COVID-19 in the New York City area. JAMA. 2020;323:2052-9.

3. Lajoie SP, Gube M. Adaptive expertise in medical education: accelerating learning trajectories by fostering self-regulated learning. Med Teach. 2018;40:809-12.

4. Mylopoulos M. Preparing future adaptive experts: why it matters and how it can be done. Med Sci Educ. 2020;30:11-2.

5. Cutrer WB, Miller B, Pusic MV, Mejicano G, Mangrulkar RS, Gruppen LD, et al. Fostering the development of master adaptive learners: a conceptual model to guide skill acquisition in medical education. Acad Med. 2017;92:70.

6. Ginzburg SB, Santen SA, Schwartzstein RM. Self-directed learning: a new look at an old concept. Med Sci Educ. 2021;31:229-30.

7. YS Lim VT Lyons JM Willey Supporting self-directed learning: a national needs analysis. Med Sci Educ [Internet]. 2021 cited 2021 Apr 29 Available from: https://doi.org/10.1007/ s40670-021-01278-y

8. White CB, Gruppen LD. Self-regulated learning in medical education. Underst Med Educ [Internet]. Wiley-Blackwell; 2010 [cited 2018 Aug 28]. p. 271-82. Available from: https://onlinelibrary. wiley.com/doi/abs/. https://doi.org/10.1002/9781444320282.ch19

9. Cutrer WB, Atkinson HG, Friedman E, Deiorio N, Gruppen LD, Dekhtyar M, et al. Exploring the characteristics and context that allow master adaptive learners to thrive. Med Teach. 2018;40:791-6.

10. Liaison Committee on Medical Education. Functions and structure of a medical school: standards for accreditation of medical education programs leading to the M.D. [Internet]. Available from: http://lcme.org/publications/\#Standards

11. Accreditation Council for Graduate Medical Education. ACGME common program requirements [Internet]. [cited 2014 Oct 25]. Available from: https://www.acgme.org/acgmeweb/Portals/0/ PFAssets/ProgramRequirements/CPRs2013.pdf 
12. Wolff M, Stojan J, Buckler S, Cranford J, Whitman L, Gruppen $\mathrm{L}$, et al. Coaching to improve self-directed learning. Clin Teach. 2020; $17: 408-12$.

13. Lloyd RB, Park YS, Tekian A, Marvin R. Understanding assessment systems for Clinical Competency Committee decisions: evidence from a multisite study of psychiatry residency training programs. Acad Psychiatry J Am Assoc Dir Psychiatr Resid Train Assoc Acad Psychiatry. 2020;44:734-40.

14. Sawatsky AP. Instruments for measuring self-directed learning and self-regulated learning in health professions education: a systematic review. :28.

15. Bandura A. Social cognitive theory in cultural context. Appl Psychol. 2002;51(2):269-90.

16. Wetzel AP, Mazmanian PE, Hojat M, Kreutzer KO, Carrico RJ, Carr C, et al. Measuring medical students' orientation toward lifelong learning: a psychometric evaluation. Acad Med. 2010;85.

17. Turan S, Demirel O, Sayek I. Metacognitive awareness and selfregulated learning skills of medical students in different medical curricula. Med Teach. 2009;31:e477-483.
18. Smith BW, Dalen J, Wiggins K, Tooley E, Christopher P, Bernard $\mathrm{J}$. The Brief Resilience Scale: assessing the ability to bounce back. Int J Behav Med. 2008;15:194-200.

19. Vandewalle D. Development and validation of a work domain goal orientation instrument. Educ Psychol Meas. SAGE Publications Inc; 1997;57:995-1015.

20. van der Vleuten CP, Schuwirth LW, Driessen EW, Dijkstra J, Tigelaar D, Baartman LK, et al. A model for programmatic assessment fit for purpose. Med Teach. 2012;34:205-14.

21. Bok HGJ, Teunissen PW, Favier RP, Rietbroek NJ, Theyse LFH, Brommer H, et al. Programmatic assessment of competency-based workplace learning: when theory meets practice. BMC Med Educ. 2013;13:123.

22. Schraw G, Dennison RS. Assessing metacognitive awareness. Contemp Educ Psychol. 1994;19(4):460-75.

Publisher's Note Springer Nature remains neutral with regard to jurisdictional claims in published maps and institutional affiliations. 